Article

\title{
Structural and Thermal Analysis of Softwood Lignins from a Pressurized Hot Water Extraction Biorefinery Process and Modified Derivatives
}

\author{
Lucas Lagerquist ${ }^{1}\left({ }^{1}\right.$, Andrey Pranovich ${ }^{1,2}$, Ivan Sumerskii ${ }^{3}$, Sebastian von Schoultz ${ }^{4}$, \\ Lari Vähäsalo ${ }^{4}$, Stefan Willför ${ }^{1}$ and Patrik Eklund ${ }^{1, * \mathbb{D}}$ \\ 1 Johan Gadolin Process Chemistry Centre, Åbo Akademi University, Biskopsgatan 8, 20500 Turku/Åbo, \\ Finland; llagerqu@abo.fi (L.L.); apranovi@abo.fi (A.P.); swillfor@abo.fi (S.W.) \\ 2 Department of Chemistry, Saint Petersburg State Forest Technical University, 194021 Saint Petersburg, Russia \\ 3 Division of Chemistry of Renewable Resources, Department of Chemistry, \\ University of Natural Resources and Life Sciences, Konrad-Lorenz-Strasse 24, A-3430 Tulln, Austria; \\ ivan.sumerskii@boku.ac.at \\ 4 CH-Bioforce Oy, Ahventie 4 A 21-22, FIN-02170 Espoo, Finland; Sebastian.schoultz@ch-bioforce.com (S.v.S.); \\ lari.vahasalo@ch-bioforce.com (L.V.) \\ * Correspondence: paeklund@abo.fi; Tel.: +358-22154720
}

Academic Editor: Derek J. McPhee

Received: 19 December 2018; Accepted: 16 January 2019; Published: 18 January 2019

\begin{abstract}
In this work we have analyzed the pine and spruce softwood lignin fraction recovered from a novel pressurized hot water extraction pilot process. The lignin structure was characterized using multiple NMR techniques and the thermal properties were analyzed using thermal gravimetric analysis. Acetylated and selectively methylated derivatives were prepared, and their structure and properties were analyzed and compared to the unmodified lignin. The lignin had relatively high molar weight and low PDI values and even less polydisperse fractions could be obtained by fractionation based on solubility in $i$-PrOH. Condensation, especially at the 5-position, was detected in this sulphur-free technical lignin, which had been enriched with carbon compared to the milled wood lignin (MWL) sample of the same wood chips. An increase in phenolic and carboxylic groups was also detected, which makes the lignin accessible to chemical modification. The lignin was determined to be thermally stable up to $\left(273-302{ }^{\circ} \mathrm{C}\right)$ based on its $\mathrm{T}_{\mathrm{dst}} 95 \%$ value. Due to the thermal stability, low polydispersity, and possibility to tailor its chemical properties by modification of its hydroxyl groups, possible application areas for the lignin could be in polymeric blends, composites or in resins.
\end{abstract}

Keywords: lignin characterization; pressurized hot water extraction; biorefinery; condensed structures; NMR analysis; thermal analysis; lignin modification

\section{Introduction}

As there is an uncertainty surrounding fossil-based raw materials, new alternative sources need to be explored for fuel and platform chemicals. Lignin is the most abundant aromatic biopolymer and could potentially be such an alternative source. The structure of lignin, in its native form, consists of phenylpropanoic units bonded together mainly by alkyl-aryl ether bonds that are formed by radical coupling reactions of the corresponding monolignols [1]. The monomeric units syringyl (S), guaiacyl $(\mathrm{G})$, and $p$-hydroxyphenyl (H) (Figure 1) will vary in occurrence based on plant species. Besides the most abundant interconnecting alkyl-aryl ether bond ( $\beta-O-4)$, many other types of interconnecting bonds between the monomeric units exist (e.g., $\alpha-O-4, \beta-1, \beta-\beta, \beta-5,5-5,4-O-5$; see examples of such linkages in Figure $2 \mathrm{~g}$ ). The native lignin in biomass differs greatly in properties, both physical and chemical, compared to lignin isolated through biomass processing. These types of isolated lignins, 
called technical or industrial lignins, are available in large volumes from the pulping industry [2], but their properties are very dependent on the isolation method [3] and on the biomass feedstock used [4].<smiles>OC/C=C/c1ccc(O)cc1</smiles>

(a)

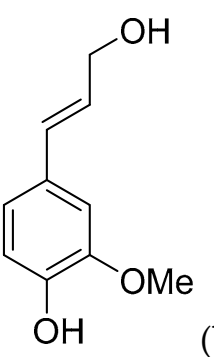

(b)

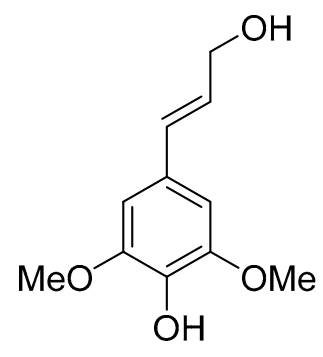

(c)

Figure 1. The lignin monomeric building blocks (a) p-coumaryl alcohol (H); (b) coniferyl alcohol (G); and (c) sinapyl alcohol (S).

The largest pulping processes-Kraft, sulfite, and soda-are currently utilizing the majority of lignin as fuel, but there are bio-refineries that are aiming to fractionate and utilize all of the biomass, which can lead to better availability of lignin for commercialization. The Lignoboost process [5], which allows the isolation of a lignin fraction from the Kraft process, is one such method but there are many other biomass fractionation technologies such as organosolv, steam explosion, acid hydrolysis, hot water extraction, and ammonia fiber expansion [6]. The different processes will yield different types of lignin, but also the same process with different process parameters [7] could affect the structure and properties of the lignin, therefore it is of great importance to properly characterize technical lignins produced by novel fractionation technologies to optimize their use in different applications, as seen from studies that compared how the chemical structure affects the product, i.e., in carbon fiber [8] and phenol-formaldehyde resin [9]. When studying lignin as a source of fuel or chemicals, the focus has often been to catalytically cleave the alkyl-aryl ether bonds $[10,11]$, and thus for such an end use, it would be preferable to have an intact lignin with large amounts of $\beta-O-4$ linkages and low degree of condensation. There are also applications when lignin is used in its polymeric form, i.e., used as a copolymer, or in polymer blends, or in composites [12-15] and in these cases condensation does not necessarily affect the properties negatively. To improve the functional properties of polymer blends, and to increase the compatibility of lignin with other polymers, chemical modification or derivatization is often necessary [16-19]. The compatibility [20] and the thermal stability [21] can be tailored by altering the derivatization agent e.g., in lignin esters by increasing the length of the esters. The innate properties of polymers can also be improved in blends with lignin as seen when poly lactic acid (PLA) was blended with fatty acid esterified lignin [22]. These blends are often thermally treated or processed, e.g., with temperatures around $170{ }^{\circ} \mathrm{C}$ for PLA $[23,24]$ and temperatures up to $220{ }^{\circ} \mathrm{C}$ for poly(ethylene oxide) blends [25]. The blending temperature can be crucial as it has been shown that lignin enhance the degradation polymers such as PLA at elevated temperatures [26].

In this article we have studied the softwood lignin fraction obtained from a novel pressurized hot water extraction (PHWE) biorefinery process $[27,28]$. In the first step of the process the hemicelluloses are isolated by extraction from wood chips with hot water (max $150{ }^{\circ} \mathrm{C}$ ) at oxygen-starved conditions [27]. After the separation of the hemicelluloses the chips are cooked with alkali in a second step to isolate the cellulose fraction as described by Schoultz et al. [28]. The lignin, called BLN lignin, can then be precipitated and purified from the black liquor. The process is currently being up-scaled for commercial applications. In our earlier work we have analyzed the structural changes that the process caused to birch lignin and showed that the process clearly affects the structure [29]. As the process caused condensation and increased the amount of free hydroxyl groups, this lignin may be more suitable for applications where it is used in its polymeric form. The main objective of this study was to investigate the structural and thermal properties of the BLN lignins from the softwoods Norway spruce and Scots pine. The lignins were also chemically modified by acetylation and methylation of the phenolic hydroxyl groups. These modifications were performed as it has 
been shown that especially free hydroxyl groups are labile to thermal treatments [30]. These types of reactions, or similar types of reactions, are also often used to increase the compatibility with other polymers. The lignin was also fractionated by solvent fractionation, which illustrates that the lignin can be further tailored into more narrow molar mass fractions by simple separation methods.

\section{Results and Discussion}

\subsection{Analysis of the Unmodified Lignin}

The structural alteration of the native lignin linkages can be seen from the HSQC spectrum of the MWL (Figure 2a, pine, and 2c, spruce) and BLN lignin (Figure 2b, pine, and Figure 2d, spruce), and the NMR shifts are listed in Table 1 . Based on the integrals of the correlation peaks the small amount of remaining $\beta-O-4$ (A) (From MWL 27 to BLN 5\% in pine and from 32 to $4 \%$ in spruce), $\beta$ - $\beta$ (B) (From MWL 7 to BLN 2\% in pine and 5 to 3\% in spruce), and $\beta-5(C)$ (From MWL 11 to BLN 3\% in pine and 15 to $3 \%$ in spruce) only constitutes a small fraction compared to the MWL and no dibenzodioxocin $(\mathrm{K})$, cinnamyl alcohol (E), cinnamyl aldehyde (I), or $\gamma$-substituted $\beta-O-4\left(\mathrm{~A}^{\prime}\right)$ could be detected in the BLN lignins. The aryl glycerol group $(\mathrm{J})$ was formed during the process and is known to be formed during soda pulping [31,32]; however, whether the group is formed during the initial PHWE or during the alkaline pulping was not confirmed. Both enol ethers (L) and stilbenes (M) could be detected in the aromatic region and guaiacyl propanol (F), and secoisolariresinol (D) in the aliphatic region. Two overlapping signals $\mathrm{B}_{\gamma^{\prime}}$ and $\mathrm{J}_{\beta}$, marked by ${ }^{*}$ in Figure $2 \mathrm{~b}, \mathrm{~d}$, was detected from an unidentified structure. This was deduced as both $\mathrm{B}_{\gamma^{\prime}}$ and $\mathrm{J}_{\beta}$ show inconsistencies in their integrals from HSQC compared to $B_{\gamma}$ and $Y_{\alpha}$. The $B_{\gamma^{\prime}}$ which should be a $\mathrm{CH}_{2}$ in the $\beta-\beta$ resinol structure is a $\mathrm{CH} / \mathrm{CH}_{3}$ in both of the multiplicity edited HSQC lignin spectra, due to the overlapping of signals. From the aldehyde region (Figure 2e,f) we detected the $\mathrm{C}_{\gamma}-\mathrm{H}$ from the cinnamyl aldehyde (I) moiety and a correlation peak originating from benzylic aldehyde (N) unit in the MWL (Figure 2e), but in the BLN lignin only the benzylic aldehyde $(\mathrm{N})$ correlation peak remains (Figure $2 \mathrm{f}$ ). There was an increase of carboxylic groups based on ${ }^{31} \mathrm{P}-\mathrm{NMR}$ (Table 2), however, it seems that not all benzylic aldehydes were oxidized to carboxylic acids during the treatment and this could be due to the oxygen removal during the process. Only small amounts of carbohydrate impurities were detected in the HSQC spectrum of the BLN lignin. It is evident that significant condensation of the lignin occurred as the native lignin linkages were reduced in amount but the lignins retain a large molar mass. The lignins were also enriched with carbon compared to the MWL as seen from the elemental analysis (Table 3).

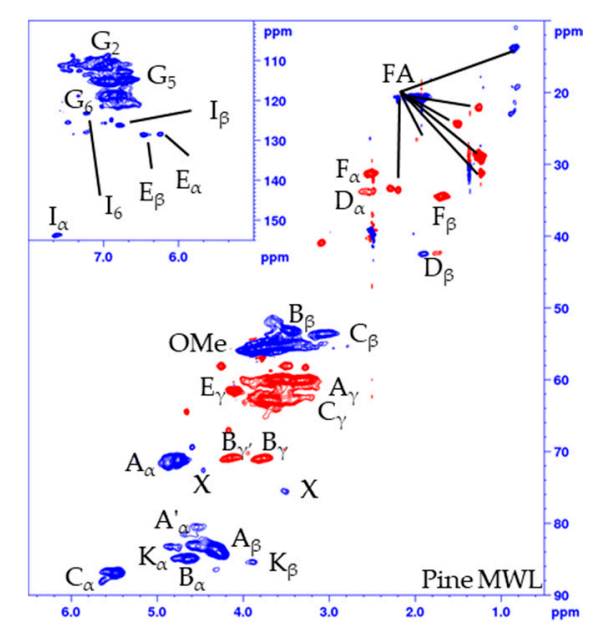

(a)

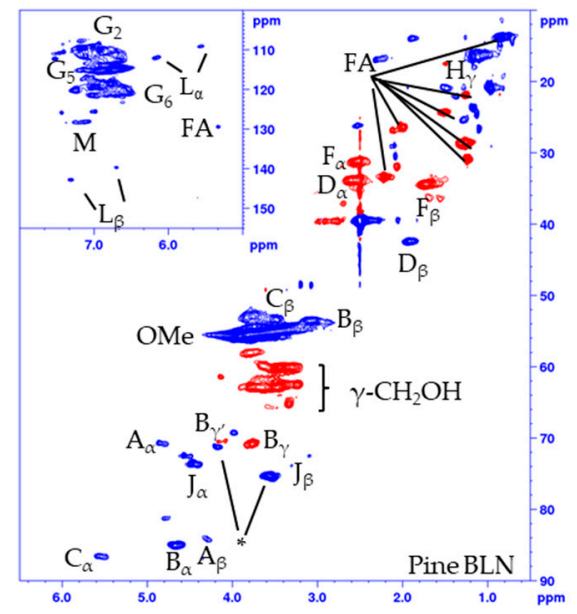

(b)

Figure 2. Cont. 


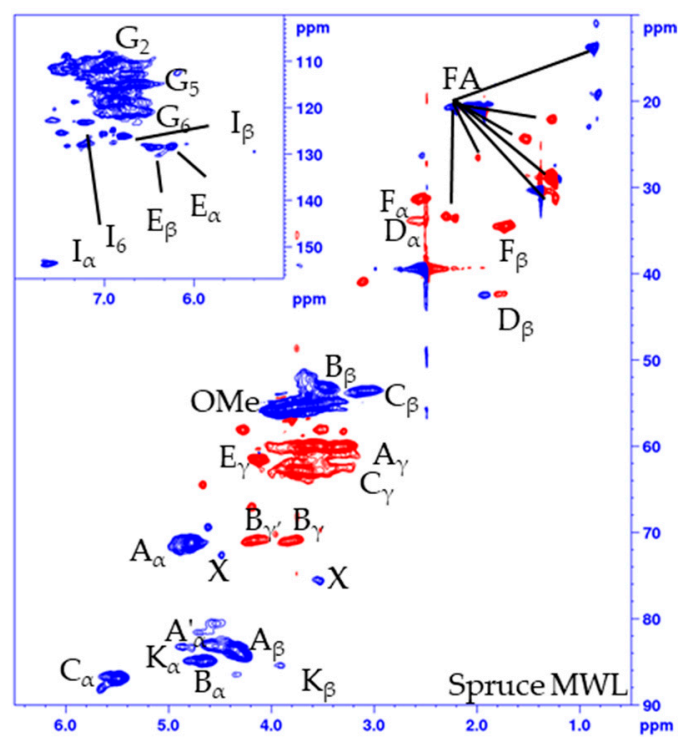

(c)

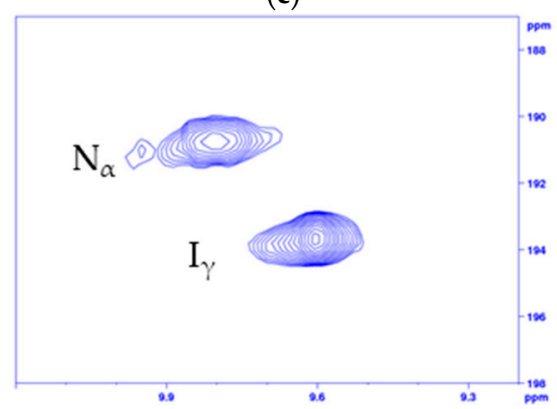

(e)

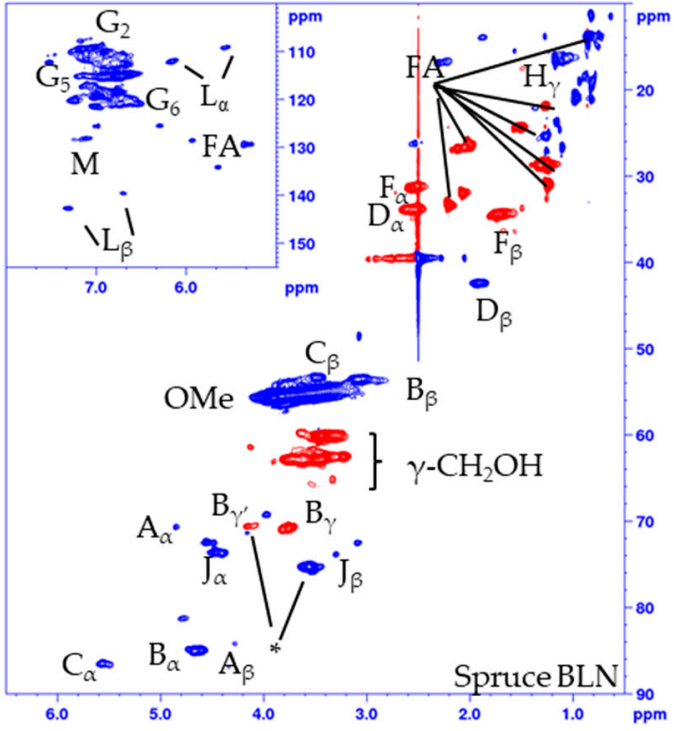

(d)

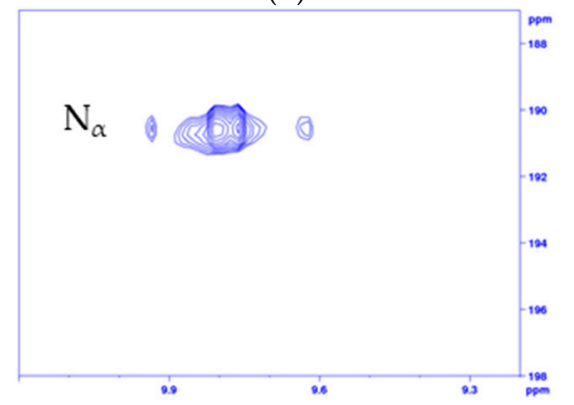

(f)<smiles>[Y]C(O)C(=O)c1ccc(OC)c(OC)c1</smiles>
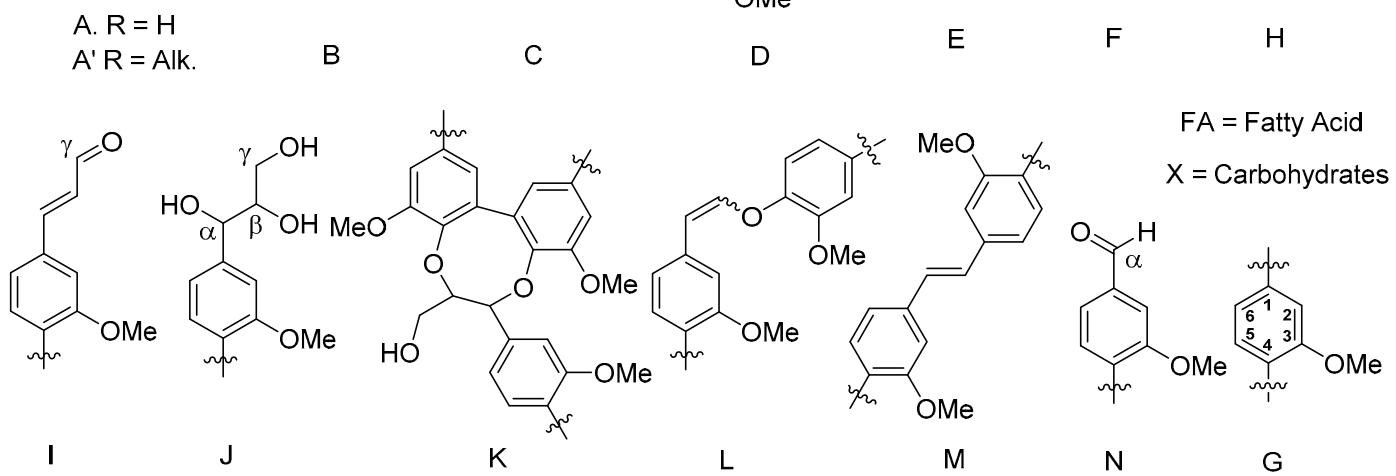

(g)

Figure 2. Multiplicity edited HSQC of (a) Pine MWL; (b) Pine BLN lignin; (c) Spruce MWL; (d) Spruce BLN lignin; (e) aldehyde region of pine MWL; (f) aldehyde region of pine BLN and (g) the corresponding structures. $\left(\mathrm{CH} / \mathrm{CH}_{3}\right.$ shown as positive (blue) and $\mathrm{CH}_{2}$ as negative (red). 
Table 1. Assignment of the identified ${ }^{13} \mathrm{C}-{ }^{1} \mathrm{H}$ cross-signals.

\begin{tabular}{|c|c|c|}
\hline Label & $\delta_{C} / \delta_{H}(p p m)$ & Assignment (C-H Correlation) \\
\hline $\mathrm{H} \gamma$ & $21.0 / 1.48$ & $\gamma$ in G-hydroxyethyl ketone \\
\hline $\mathrm{F}_{\alpha}$ & $31.2 / 2.51$ & $\alpha$ in G-propanol \\
\hline $\mathrm{D}_{\alpha}$ & $33.9 / 2.53$ & $\alpha$ in secoisolariresinol \\
\hline $\mathrm{F}_{\beta}$ & $34.4 / 1.70$ & $\beta$ in G-propanol \\
\hline $\mathrm{D}_{\beta}$ & $42.5 / 1.89$ & $\beta$ in secoisolariresinol \\
\hline$C_{\beta}$ & $53.1 / 3.47$ & $\beta$ in phenylcoumaran \\
\hline $\mathrm{B}_{\beta}$ & $53.5 / 3.06$ & $\beta$ in resinol $(\beta-\beta)$ \\
\hline $\mathrm{OMe}$ & $55.5 / 3.76$ & Methoxy peaks \\
\hline $\mathrm{A}_{\gamma}$ & $59.9 / 3.61$ & $\gamma$ in $\beta-O-4$ \\
\hline $\mathrm{E} \gamma$ & $61.5 / 4.10$ & $\gamma$ in cinnamyl alcohol \\
\hline $\mathrm{C} \gamma$ & $62.8 / 3.73$ & $\gamma$ in phenylcoumaran \\
\hline $\mathrm{J}_{\gamma}$ & $62.8 / 3.47$ & $\gamma$ in arylglycerol \\
\hline $\mathrm{B}_{\gamma}$ & $70.8 / 4.16$ and 3.73 & $\gamma$ in resinol \\
\hline $\mathrm{A}_{\alpha}$ & $71.06 / 4.76$ & $\alpha$ in $\beta-O-4$ \\
\hline $\mathrm{J}_{\alpha}$ & $73.5 / 4.45$ & $\alpha$ in arylglycerol \\
\hline $\mathrm{J}_{\beta}$ & $75.4 / 3.56$ & $\beta$ in arylglycerol \\
\hline $\mathrm{K}_{\alpha}$ & $83.2 / 4.84$ & $\alpha$ in dibenzodioxocin \\
\hline$A_{\beta}$ & $84.0 / 4.30$ & $\beta$ in $\beta-O-4$ \\
\hline $\mathrm{B}_{\alpha}$ & $84.9 / 4.64$ & $\alpha$ in resinol $(\beta-\beta)$ \\
\hline $\mathrm{K}_{\beta}$ & $85.4 / 3.89$ & $\beta$ in dibenzodioxocin \\
\hline $\mathrm{C}_{\alpha}$ & $87.0 / 5.47$ & $\alpha$ in phenylcoumaran \\
\hline $\mathrm{L}_{\alpha}$ & $108.9 / 5.56$ & aryl enol ether \\
\hline $\mathrm{G}_{2}$ & $110.3 / 6.94$ & 2 in the guaiacyl unit \\
\hline $\mathrm{L}_{\beta}$ & $112.1 / 6.17$ & Aryl enol ether \\
\hline $\mathrm{G}_{5}$ & $115.2 / 6.85$ & 5 in the guaiacyl unit \\
\hline $\mathrm{G}_{6}$ & $118.9 / 6.83$ & 6 in the guaiacyl unit \\
\hline $\mathrm{I}_{6}$ & $123.2 / 7.22$ & 6 in cinnamyl aldehyde \\
\hline $\mathrm{I}_{\beta}$ & $126.3 / 6.77$ & $\beta$ in cinnamyl aldehyde \\
\hline$M$ & $128.3 / 7.12$ & Stillbene \\
\hline $\mathrm{E}_{\alpha}$ & $128.4 / 6.24$ & $\alpha$ in cinnamyl alcohol \\
\hline $\mathrm{E}_{\beta}$ & $128.5 / 6.46$ & $\beta$ in cinnamyl alcohol \\
\hline $\mathrm{L}_{\alpha^{\prime}}$ & $139.8 / 6.71$ & Aryl enol ether \\
\hline $\mathrm{L}_{\beta^{\prime}}$ & $143.0 / 7.31$ & Aryl enol ether \\
\hline $\mathrm{I}_{\alpha}$ & $153.7 / 7.61$ & $\alpha$ in cinnamyl aldehyde \\
\hline $\mathrm{N}_{\alpha}$ & $190.8 / 9.80$ & Benzylic aldehyde \\
\hline $\mathrm{I}_{\gamma}$ & $193.8 / 9.60$ & $\gamma$ in cinnamyl aldehyde \\
\hline
\end{tabular}

The fragmentation and condensation can occur during the slightly acidic PHWE phase and/or during the alkali pulping, the mechanism can be either ionic and/or radical and will most likely occur at the $\mathrm{C}_{\alpha}, \mathrm{C}_{5}$, or $\mathrm{C}_{6}$ position. The formation of condensed 5-substituted phenolic structures is seen from the ${ }^{31} \mathrm{P}-\mathrm{NMR}$ spectrum as they are detected separately from the aliphatic and guaiacylic hydroxyl groups (see Supporting Data). The condensation was also seen from the HSQC of the methylated BLN lignin (Figure 3), where only the correlation peak of the methylated 4-OMe in 5-condensed structures was shifted to $\delta_{\mathrm{C}} / \delta_{\mathrm{H}}(60.1 / 3.72) \mathrm{ppm}$ (Figure 3b,c) and all other aromatic OMe-peaks will remain at approximately $\delta_{\mathrm{C}} / \delta_{\mathrm{H}}(55.5 / 3.76) \mathrm{ppm}$. From our previous work on birch lignin we detected evidence of significant 6-C condensation of the aromatic ring, this was detected as the chemical shift of the 5-OMe in the syringylic unit was shifted in a similar manor as the 4-OMe in the 5-condensed methylated guaiacyl unit. We did not see any such shift in the softwoods due to the fact that a condensation on the 6-position in guaiacyl units would not yield an OMe-group which has two neighboring substituents, which leads to the increase in the chemical shift. The broadening and slight shift of the HSQC correlation peaks of $\mathrm{C}_{2}-\mathrm{H} \delta_{\mathrm{C}} / \delta_{\mathrm{H}}(110.3 / 6.94)$ to $(112.0 / 6.79) \mathrm{ppm}$ and $\mathrm{C}_{6}-\mathrm{H} \delta_{\mathrm{C}} / \delta_{\mathrm{H}}$ $(118.9 / 6.83)$ to $(120.3 / 6.66) \mathrm{ppm}$ compared to that of the MWL is caused by, among other things, the 5 -condensation of the guaiacyl units [33]. The integrals of the aromatic $\mathrm{C}_{2}-\mathrm{H}, \mathrm{C}_{5}-\mathrm{H}$ and $\mathrm{C}_{6}-\mathrm{H}$ from the HSQC correlation peaks gave us an indication of the condensation pattern and showed the least 
amount of $\mathrm{C}_{5}-\mathrm{H}$ followed by $\mathrm{C}_{2}-\mathrm{H}$ and $\mathrm{C}_{6}-\mathrm{H}$. However, as we have a clear reduction in aliphatic side chains there will most likely also be $\mathrm{C}_{1}-\mathrm{C}_{\alpha}$ cleavage and the chemical shift of the formed $\mathrm{C}_{1}-\mathrm{H}$ is similar to that of $\mathrm{C}_{6}-\mathrm{H}$, as seen from model compounds [34], which would give an inflated value of the amount of $\mathrm{C}_{6}-\mathrm{H}$. Other issues with the aromatic signals is the broadening of the signals, and especially as $\mathrm{C}_{2}-\mathrm{H}$ and $\mathrm{C}_{6}-\mathrm{H}$ will be more affected by changes to the side chain compared to $\mathrm{C}_{5}-\mathrm{H}$ but also the increase of free phenolic guaiacyl units will affect the chemical shifts of $\mathrm{C}_{2}-\mathrm{H}, \mathrm{C}_{5}-\mathrm{H}$ and $\mathrm{C}_{6}-\mathrm{H}$ compared to the etherified shifts. Due to the many factors that can affect the chemical shift of the aromatic signal, their integrals should only be considered as semi-quantitative.

Table 2. Amount of free hydroxyl groups in $\mathrm{mmol} / \mathrm{g}$ based on ${ }^{31} \mathrm{P}$ NMR analysis.

\begin{tabular}{|c|c|c|c|c|c|c|}
\hline Lignin & $\begin{array}{c}\text { Aliphatic } \\
(150.0-145.5 \text { ppm })^{1}\end{array}$ & $\begin{array}{c}\text { 5-subs } \\
(145.1-140.5 \text { ppm) }\end{array}$ & $\begin{array}{c}\text { G-units } \\
(140.5-136.8 \text { ppm) }\end{array}$ & $\mathrm{Ph}-\mathrm{OH}$ & $\begin{array}{c}\text { OH } \\
\text { Total }\end{array}$ & $\begin{array}{c}\text { COOH } \\
(136.8-133.4 \text { ppm) }\end{array}$ \\
\hline Pine MWL & 4.7 & 0.8 & 1.2 & 2.0 & 6.7 & 0.3 \\
\hline Pine BLN & 2.2 & 2.0 & 1.9 & 3.9 & 6.1 & 0.6 \\
\hline Pine MTBE & 0.7 & 1.2 & 2.5 & 3.7 & 4.4 & 1.6 \\
\hline Pine iPrOH insol & 1.9 & 1.8 & 1.5 & 3.3 & 5.2 & 0.4 \\
\hline Pine iPrOH sol & 1.7 & 1.8 & 2.3 & 4.0 & 5.7 & 0.8 \\
\hline Spruce MWL & 4.6 & 0.8 & 1.3 & 2.1 & 6.7 & 0.2 \\
\hline Spruce BLN & 2.2 & 1.9 & 1.9 & 3.9 & 6.1 & 0.6 \\
\hline Spruce MTBE & 1.0 & 1.3 & 2.3 & 3.6 & 4.6 & 1.4 \\
\hline Spruce iPrOH insol & 2.1 & 1.9 & 1.6 & 3.5 & 5.6 & 0.5 \\
\hline Spruce iPrOH sol & 1.6 & 1.7 & 2.1 & 3.8 & 5.4 & 0.8 \\
\hline OMe Pine BLN & 2.0 & & & 0.8 & 2.8 & 0.7 \\
\hline OMe Spruce BLN & 1.9 & & & 0.6 & 2.5 & 0.6 \\
\hline OMe Birch BLN & 1.3 & & & 0.5 & 1.8 & 0.7 \\
\hline
\end{tabular}

${ }^{1} 150.0-145.5$ ppm when c-hexanol was used as internal standard.

Table 3. The molar mass of the different lignin fractions and elemental analysis of the unmodified lignin and the MWLs.

\begin{tabular}{|c|c|c|c|c|}
\hline Lignin & $M_{n}(g / m o l)$ & \multicolumn{2}{|c|}{$M_{w}(g / m o l)$} & PDI \\
\hline Pine MWL & 1500 & \multicolumn{2}{|c|}{2700} & 1.7 \\
\hline Pine BLN & 3200 & \multicolumn{2}{|c|}{6700} & 2.1 \\
\hline Pine MTBE & 380 & \multicolumn{2}{|c|}{480} & 1.3 \\
\hline Pine iPrOH insol & 4200 & \multicolumn{2}{|c|}{8000} & 1.9 \\
\hline Pine iPrOH sol & 860 & \multicolumn{2}{|c|}{1500} & 1.7 \\
\hline Spruce MWL & 2100 & \multicolumn{2}{|c|}{3000} & 1.5 \\
\hline Spruce BLN & 2100 & \multicolumn{2}{|c|}{5500} & 2.7 \\
\hline Spruce MTBE & 460 & \multicolumn{2}{|c|}{570} & 1.2 \\
\hline Spruce iPrOH insol & 3800 & \multicolumn{2}{|c|}{7000} & 1.9 \\
\hline \multirow[t]{2}{*}{ Spruce iPrOH sol } & 890 & \multicolumn{2}{|c|}{1200} & 1.3 \\
\hline & $\mathrm{C}(\%)$ & H (\%) & N (\%) & $\mathrm{O}(\%)$ \\
\hline Pine MWL & 60.6 & 5.9 & 0.2 & 33.3 \\
\hline Pine BLN & 67.2 & 6.0 & 0.1 & 26.7 \\
\hline Spruce MWL & 59.5 & 5.7 & 0.1 & 34.7 \\
\hline Spruce BLN & 66.5 & 5.8 & 0.0 & 27.6 \\
\hline
\end{tabular}

\subsection{Acetylated and Methylated Lignin}

The degree of substitution of the acetylated and methylated lignin was determined by ${ }^{31}$ P-NMR (see Supporting Data). The acetylated lignin contained no free hydroxyl groups and the HSQC-spectrum showed characteristic correlation peaks for acetylated structures (see Supporting Data). For the analysis of the thermal properties we used $\mathrm{Me}_{2} \mathrm{SO}_{4}$ in alkaline aqueous media to selectively methylate the phenolic hydroxyl groups in the lignin and to leave the aliphatic hydroxyl groups and carboxyl groups unmodifed (see Table 2). The small amounts of remaining free phenolic groups seen in Table 2 seemed, based on ${ }^{31} \mathrm{P}-\mathrm{NMR}$ shifts of the peaks, to originate from hydroxyl groups in 5-condensed structures. To fully methylate one lignin sample, $\mathrm{CH}_{3} \mathrm{I}$ was used as methylation agent and $\mathrm{NaH}$ as base in anhydrous DMF (Figure 3c). This sample was only used to compare the 
structural differences between the unmodified (Figure 3a), methylated phenolic (Figure 3b), and fully methylated lignin (Figure 3c). The HSQC correlation peaks in the oxygenated aliphatic area can be seen in Figure 3. The selectively methylated lignin (Figure 3b) remained similar to the starting material (Figure 3a), with no changes detected in the structures originating from natively occurring lignin linkages.

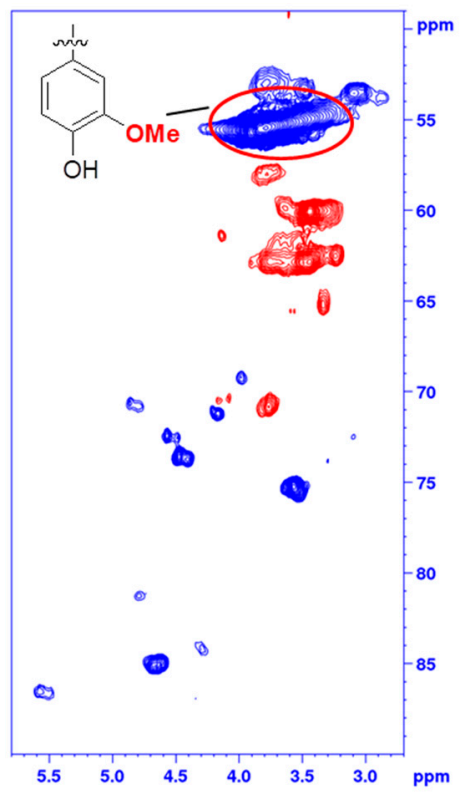

(a)

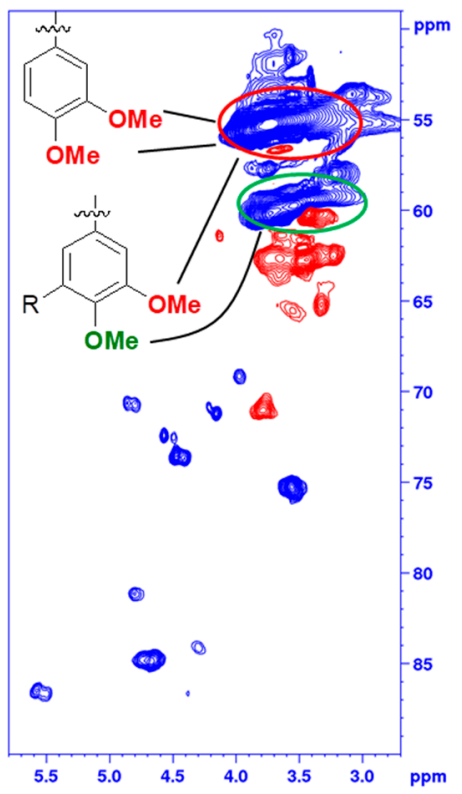

(b)

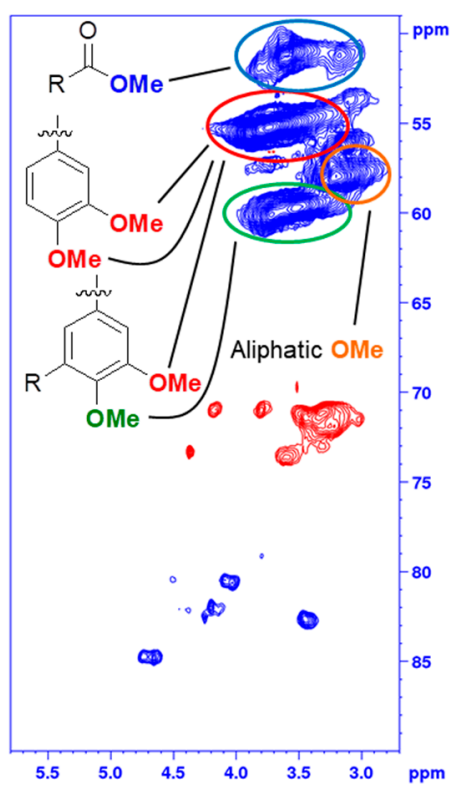

(c)

Figure 3. Multiplicity edited HSQC of the oxygenated aliphatic area of (a) Pine BLN lignin; (b) selectively methylated Pine BLN lignin and (c) fully methylated Pine BLN lignin. ( $\mathrm{CH} / \mathrm{CH}_{3}$ shown as positive (blue) and $\mathrm{CH}_{2}$ as negative (red).

The only difference between Figure $3 a, b$ is the slightly higher chemical shift, in the ${ }^{13} \mathrm{C}-\mathrm{NMR}$ spectrum, of the 4-OMe in structures that has been condensed on the 5-position. This change in chemical shift can also be seen in model compounds with the same type of structure [34]. In the fully methylated derivative (Figure 3c) all the traditionally occurring C-H correlation peaks, besides the $\beta-\beta$ signals that lack hydroxyl groups in the structure, were shifted to a higher ppm value due to the methylation of the aliphatic hydroxyl groups. The methyl ester group and the aliphatic methyl ether groups were also clearly detected separately (Figure 3c). In the aromatic area of the methylated lignin only the $\mathrm{C}_{5}-\mathrm{H}$ correlation peak was shifted to a lower ${ }^{13} \mathrm{C}$ shift, in accordance with the fact that it will be more affected by the methylation than the $\mathrm{C}_{2}-\mathrm{H}$ and $\mathrm{C}_{6}-\mathrm{H}$.

\subsection{MTBE-Soluble and i-PrOH Fractions}

The lignin precipitated from the black liquor was fractionated to MTBE insoluble lignin (BLN) and MTBE soluble lignin (see Scheme 1). The MTBE soluble fraction, $\sim 15 \mathrm{w} \%$ of the total amount isolated, contained low molar mass compounds, mainly wood extractives and a complex mixture of phenolic compounds. Some polymeric or oligomeric lignin was also detected from the characteristic signals of the aromatic- and methoxyl groups in the HSQC spectrum (Figure 4). Large amounts of aliphatic, aromatic, and olefinic correlation signals was seen, origination from various lignin degradation products and wood extractives. The HSQC spectrum lacks all the traditional lignin structures as seen from the oxygenated aliphatic area. Large amounts of carboxylic groups and small amounts of aliphatic hydroxyl groups was detected in this fraction based on the ${ }^{31} \mathrm{P}-\mathrm{NMR}$ analysis (Table 2), which is consistent with wood extractives and lignin degradation products. The MTBE insoluble lignin (BLN lignin) was separated to a high and medium molar mass portion by $i-\mathrm{PrOH}$ solvent fractionation (see Scheme 1 and Table 3). The method allows us to prepare lignin with a more narrow molar mass. 
Solvent fractionation is a common method to separate lignin based on size and a wide array of solvents, or solvent mixtures, has been used for this purpose $[35,36]$.

Structurally the $i-\mathrm{PrOH}$ insoluble portion $(\sim 70 \mathrm{w} \%)$ had a larger molecular mass than the $i-\mathrm{PrOH}$ soluble portion $(\sim 30 \mathrm{w} \%)$. It also contained a smaller amount of carboxylic groups and free phenolic G-units compared to the $i$-PrOH soluble fraction. The majority of low molar mass compounds were removed from the starting lignin during the MTBE extraction, but small amounts was still detected in the $i-\mathrm{PrOH}$ soluble fraction. All of the fractions had a narrower PDI value than the BLN lignin. Low PDI values in lignin are a favorable parameter in producing functional materials as it reduces the complexity of the polymer [19].

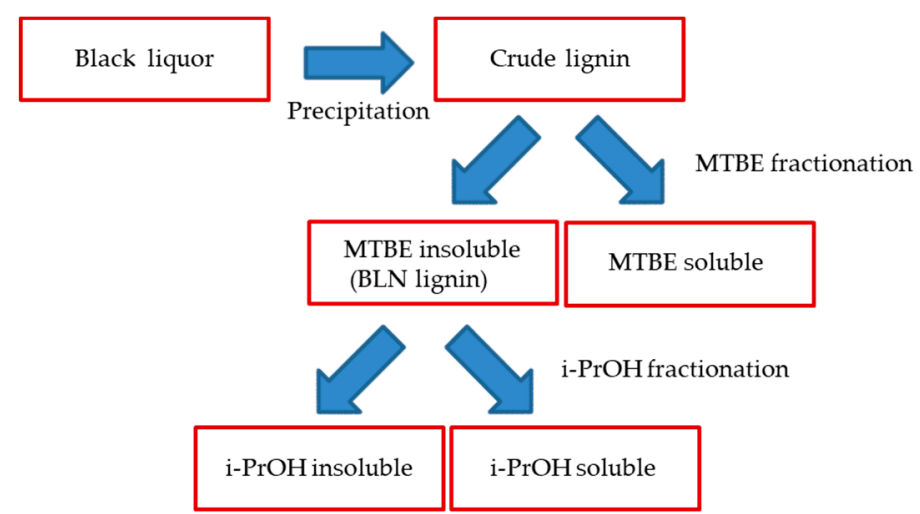

Scheme 1. Scheme of the lignin fractionation.

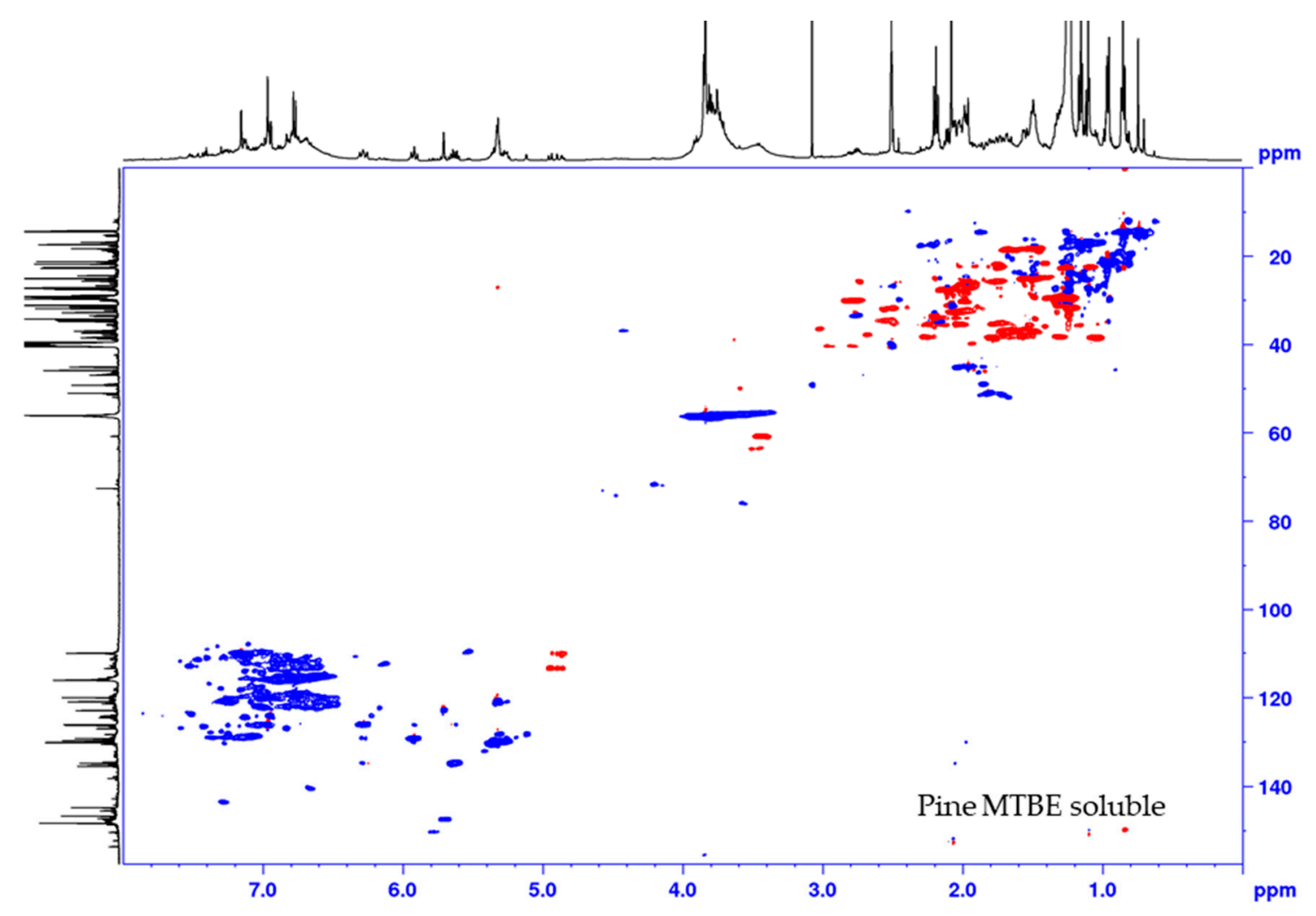

(a)

Figure 4. Cont. 


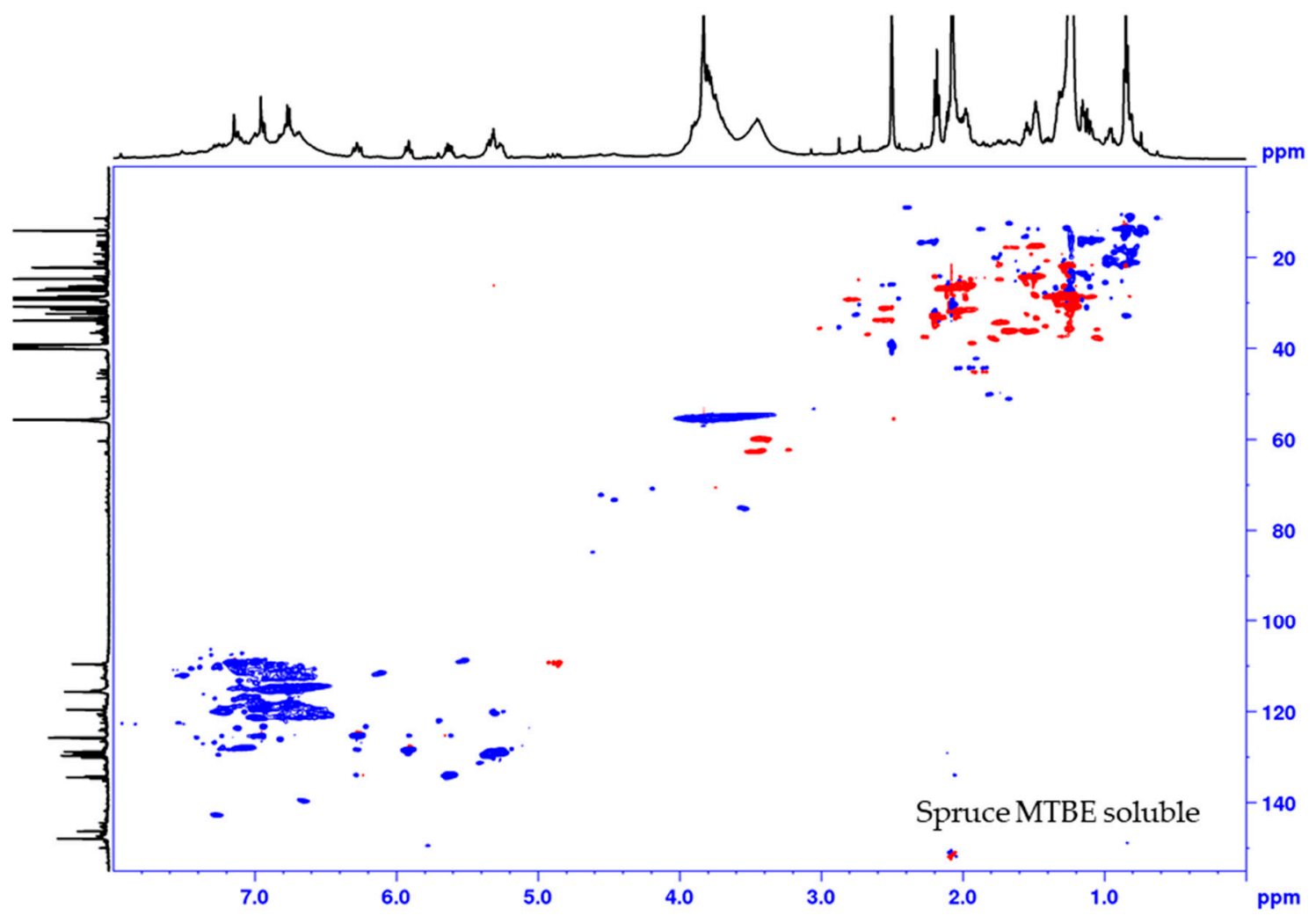

(b)

Figure 4. Multiplicity edited HSQC of the MTBE soluble fraction from the process of (a) pine and (b) spruce. $\mathrm{CH} / \mathrm{CH}_{3}$ shown as positive (blue) and $\mathrm{CH}_{2}$ as negative (red).

\subsection{Thermal Properties}

TGA was used to determine the thermal stability and decomposition of the lignin samples (Figure 5). A birch lignin (Figure 5a) from the same process was used to compare the thermal properties between softwood and hardwood lignin (Table 4). According to the literature the degradation of the lignin structure starts at $230-260{ }^{\circ} \mathrm{C}$ with the degradation of the propanoid side chain and then continues to cleave the linkages bonded with C-C bonds at $275-350{ }^{\circ} \mathrm{C}$ [37]. The relatively high $\mathrm{T}_{\mathrm{dst}} 95 \%$ values of $273-302{ }^{\circ} \mathrm{C}$ for the unmodified lignins indicated low amounts of phenylpropanoid side chains and aryl ether linkages and that the lignin was bonded by more stable C-C bonds, which is in agreement with our structural analysis of the lignin. The methylation of the phenolic groups slightly increased the stability of all the lignin samples compared to the unmodified lignin, as seen from the $\mathrm{T}_{\mathrm{dst}} 95 \%$ values (Table 4 ). The acetylation decreased the stability which is contradictory to other studies [38], this indicate that the acetyl groups were cleaved or that the decrease in mass is due to evaporation of less volatile compounds. The cleavage could be catalyzed by some impurity, such as minuscule amounts of acetic acid from the reaction. To study this phenomenon two samples, unmodified pine lignin and acetylated pine lignin, were dried extensively at elevated temperature prior to analysis. The results (see Supporting Data) showed an slight increase in the $\mathrm{T}_{\mathrm{dst}} 95 \%$ value for the acetylated sample from the initial value of 233 to $264^{\circ} \mathrm{C}$, which can partially be explained by the more efficient removal of volatiles, however, the $\mathrm{T}_{\mathrm{dst}} 95 \%$ value was still lower than the $284^{\circ} \mathrm{C}$ of the unmodified lignin, which could be due to that the cleaved acetyl groups can act as catalyst for further deacetylation. The acetylated lignins still had high $\mathrm{T}_{\mathrm{dst}} 95 \%$ values which make acetylation a viable option to increase the compatibility of lignin with other polymers. The thermal stability can also be increased by performing the same esterification procedure with esters with longer chains. By adjusting the chain of the esters the chemical properties of the lignin can be tailored to increase the compatibility 
with specific polymers [14]. The use of this lignin in polymer blends could be promising, based on the $\mathrm{T}_{\mathrm{dst}} 95 \%$ values, as blend processing temperatures are considerable lower, however, it is clear that the lignin starts to lose mass at lower temperatures and as seen from Cicala et al. [26] the processing stability of a lignin/PLA blend was considerably decreased at $190{ }^{\circ} \mathrm{C}$ compared to $170{ }^{\circ} \mathrm{C}$. The DTG maxima of the different samples were between $386-411^{\circ} \mathrm{C}$ with the methylated lignin slightly higher. The unmodified lignin had a higher char residue at $600{ }^{\circ} \mathrm{C}(\mathrm{wt} \%)$ than the methylated lignin, which could be due to the formation of more stable condensed structures in the unmodified lignin with free phenolic groups, while the acetylated samples had a lower char residue.

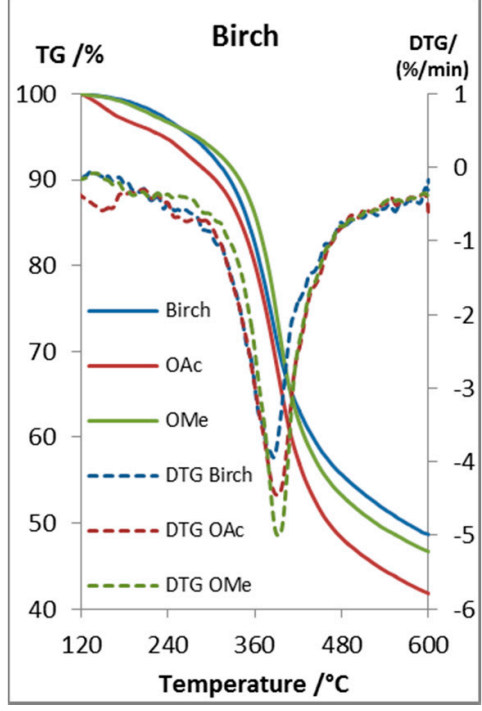

(a)

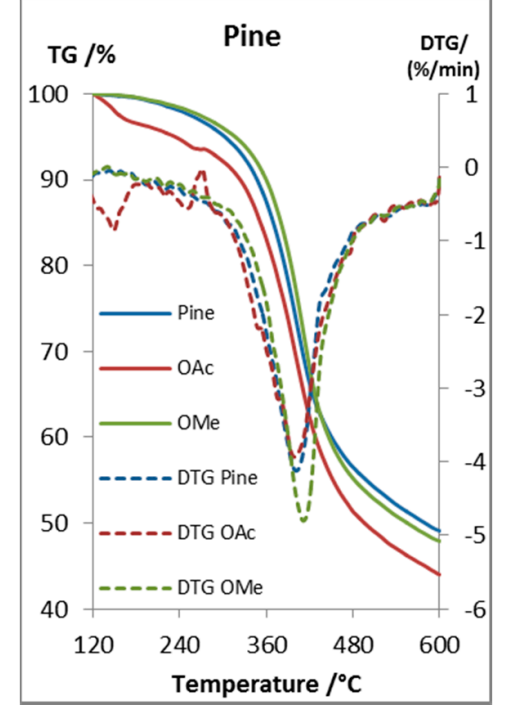

(b)

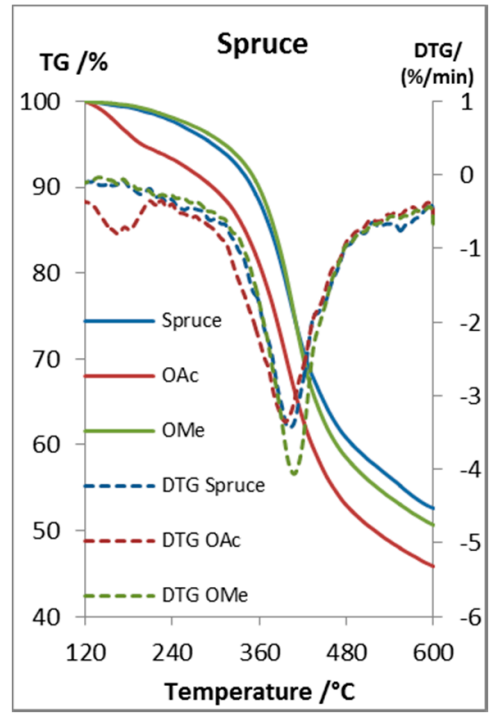

(c)

Figure 5. TG and DTG curves of (a) birch, (b) pine, and (c) spruce lignin and their acetylated and selectively methylated derivative.

Table 4. Thermal properties of pine, spruce, and birch lignin and their acetylated and methylated derivatives.

\begin{tabular}{cccc}
\hline Lignin & $\mathbf{T}_{\mathbf{d s t} \mathbf{9 5 \%}}\left({ }^{\circ} \mathbf{C}\right)$ & $\mathbf{T}_{\boldsymbol{d} \mathbf{m a x}}\left({ }^{\circ} \mathbf{C}\right)$ & Char Residue at $\mathbf{6 0 0}{ }^{\circ} \mathbf{C} \mathbf{~ ( w t ~ \% ) ~}$ \\
\hline Pine BLN & 302 & 401 & 49 \\
OAc Pine BLN & 233 & 398 & 44 \\
OMe Pine BLN & 317 & 411 & 48 \\
Spruce BLN & 296 & 401 & 53 \\
OAc Spruce BLN & 198 & 396 & 46 \\
OMe Spruce BLN & 312 & 408 & 51 \\
Birch BLN & 273 & 386 & 49 \\
OAc Birch BLN & 234 & 391 & 42 \\
OMe Birch BLN & 280 & 392 & 47 \\
\hline
\end{tabular}

\section{Materials and Methods}

\subsection{Materials}

All reagents were purchased from Sigma Aldrich (Espoo, Finland) if not stated otherwise and used without further purification. Milled Wood Lignin (MWL) was prepared according to a previously published procedure [39].

\subsection{BLN Process}

The pressurized hot water extraction process has been described elsewhere [27]. In short, wood chips of Norway spruce (Picea abies) or Scots pine (Pinus sylvestris) were first extracted with hot water 
to remove the hemicelluloses, and then the remaining fibers were further cooked with $\mathrm{NaOH}$ to give the black liquor that was separated from the pulp [28]. For the thermal analysis also birch lignin (Betula pendula) from the same process was used and has been characterized elsewhere [29].

\subsubsection{Precipitation, Purification and Fractionation}

The lignin was precipitated from the black liquor by addition of $1 \mathrm{M} \mathrm{HCl}$ until the $\mathrm{pH}$ was 2.5 . The lignin was then collected either by careful filtration. The lignin cake was then washed and collected five times with water acidified to $\mathrm{pH} 2.5$ with $\mathrm{HCl}$. After the final wash the lignin slurry was extracted 10 times with MTBE. Both the solid BLN fraction and the MTBE-soluble fraction was dried and analyzed.

\subsection{2. $\mathrm{iPrOH}$ Fractionation}

Purified BLN lignin (MTBE insoluble fraction, $1.0 \mathrm{~g}$ ) was stirred with $\mathrm{iPrOH}(40 \mathrm{~mL})$ for $1 \mathrm{~h}$ and then centrifuged. After centrifugation the $\mathrm{iPrOH}$ was decanted off and the process was repeated 10 times. The $\mathrm{iPrOH}$ insoluble (iPrOH insol) and $\mathrm{PrOH}$ soluble (iPrOH sol) fractions were collected separately, dried, and analyzed.

\subsection{Elemental Analysis}

Elemental analysis was performed on a FLASH 2000 organic elemental analyzer (Thermo Fischer Scientific, Cambridge, UK). No sulphur was detected and the oxygen content was calculated by subtracting the sum of carbon, hydrogen and nitrogen from $100 \%$.

\subsection{Molar Mass Distribution}

Molar-mass characteristics was analysed using a Shimadzu (Shimadzu Corp., Kyoto, Japan) HPLC system (SCL-10AVP system controller + DGU-14A on-line degasser + FCV-10ALVP low-pressure gradient valve + LC-10ATVP HPLC pump + SIL-20AHT autosampler + CTO-10ACVP column oven) equipped with a sequentially connected guard column $(50 \mathrm{~mm} \times 7.8 \mathrm{~mm})$ and two Jordi Gel DVB 500A (300 mm $\times 7.8 \mathrm{~mm}$ ) columns in series (Columnex LLC, New York, NY, USA). Eluent: THF with $1 \%$ acetic acid, flow rate: $0.8 \mathrm{~mL} / \mathrm{min}$, column oven temperature $40^{\circ} \mathrm{C}$. Injection volume of the autosampler was $50 \mu \mathrm{L}$. Detector: LT-ELSD detector (SEDEX 85 LF Low-Temperature Evaporative Light Scattering Detector, (SEDERE, Alfortville, France). Detector parameters: HPLC nebulizer, $40{ }^{\circ} \mathrm{C}$, air pressure: 3.5 bar, gain 3, no-split mode. Columns calibration was performed using Mono-Disperse Polystyrene Standards (Perkin-Elmer, Norwalk, CT, USA).

\subsection{NMR Spectroscopy}

All the NMR experiments were performed at $298 \mathrm{~K}$ in DMSO- $\mathrm{d}_{6}$ on an AVANCE III spectrometer (Bruker Biospin $\mathrm{GmbH}$, Rheinstetten, Germany) operating at $500.13 \mathrm{MHz}$ for ${ }^{1} \mathrm{H}, 125.77 \mathrm{MHz}$ for ${ }^{13} \mathrm{C}$ and $202.46 \mathrm{MHz}$ for ${ }^{31} \mathrm{P}$. The ${ }^{13} \mathrm{C}-\mathrm{NMR}$ were measured with a spectral width of $35,714 \mathrm{~Hz}, 2 \mathrm{~s}$ acquisition and a $10 \mathrm{~s}$ relaxation delay with the Bruker pulseprogram zgig. HSQC experiments used the Bruker's pulse program "hsqcedetgpsisp2.3 for multiplicity edited with a spectral width of $8012 \mathrm{~Hz}$ (from 0-16 ppm) and 30,182 Hz (from 0-220 ppm) for the ${ }^{1} \mathrm{H}$ - and ${ }^{13} \mathrm{C}$-dimensions. A semi quantitative method was used for calculating the amounts of lignin linkages by using the $\mathrm{C}_{2}-\mathrm{H}$ integral as internal standard (IS). A common standard protocol was used for ${ }^{31} \mathrm{P}$ NMR sample preparation [40]. To a solution of $20 \mathrm{mg}$ lignin in a $0.4 \mathrm{~mL}$ mixture of pyridine and $\mathrm{CDCl}_{3}(1.6: 1, v / \mathrm{v})$ $0.100 \mathrm{~mL}$ of a IS solution $(0.12 \mathrm{M})$ was added. After thorough stirring, $0.1 \mathrm{~mL}$ of phosphitylation reagent [2-chloro-4,4,5,5-tetramethyl-1,3,2-dioxaphospholane (TMDP)] and $0.050 \mathrm{~mL}$ of a $\mathrm{Cr}$ (acac) 3 solution $(11.4 \mathrm{mg} / \mathrm{mL})$ was added and the sample was stirred at room temperature before transferred to a NMR tube. The ${ }^{31} \mathrm{P}$ NMR measurements were collected with a $2.0 \mathrm{~s}$ acquisition time and a $5.0 \mathrm{~s}$ relaxation delay. The spectra were calibrated using the signal of the water-derivatized signal at 
132.2 ppm. For the MWLs and BLN lignin cyclohexanol was used as internal standard. For the MTBE soluble and IPA fractionated lignin $N$-hydroxy-5-norbornene-2,3-dicarboxylic acid imide (e-HNDI) was used to avoid overlapping of impurities with the IS.

\subsection{Thermal Analysis}

TGA was carried out using a STA 409 PG/1/G Luxx (NETZSCH-Gerätebau GmbH, Selb, Germany) in the range of the temperature 23 to $600{ }^{\circ} \mathrm{C}$ at a rate of $10^{\circ} \mathrm{C} / \mathrm{min}$ under $\mathrm{N}_{2}$ atmosphere. As the different samples: unmodified lignin, acetylated lignin, and lignin with methylated phenolic groups had different workup procedures prior to drying under vacuum, the $100 \mathrm{wt} \%$ was set to the value when the samples had been heated to $120{ }^{\circ} \mathrm{C}$ during the analysis. Any prior weight losses correspond to the loss of moisture or volatile compounds, and it was concluded that at $\sim 120^{\circ} \mathrm{C}$ the weight loss had stabilized based on DTG. To study the possible deacetylation two samples, unmodified pine lignin and acetylated pine lignin, was dried under vacuum at $60^{\circ} \mathrm{C}$ over one week to ensure removal of any traces of acetic acid and then analyzed by TGA. The samples were also preheated to $100{ }^{\circ} \mathrm{C}$ and cooled prior to analysis to ensure removal of moisture that could have been absorbed on the lignin during transfer to the instrument.

\subsection{Acetylation}

Lignin $(100 \mathrm{mg})$ was dissolved in pyridine $(1.0 \mathrm{~mL})$ and acetic anhydride $(1.0 \mathrm{~mL})$ was added. The mixture was stirred in darkness for 3 days before the reaction mixture was cooled and quenched by addition of $\mathrm{MeOH}$ and evaporated under reduced pressure. The crude product was redissolved in $\mathrm{CHCl}_{3}$, extracted three times with $0.1 \mathrm{M} \mathrm{HCl}$, twice with water, dried with $\mathrm{Na}_{2} \mathrm{SO}_{4}$, and finally concentrated under vacuum with isolated yields over $90 \%$.

\subsection{Methylation}

A previously reported method for methylation of the phenolic hydroxyl groups was used [41]. In short, the lignin $(1.0 \mathrm{~g})$ was dissolved in $0.7 \mathrm{M} \mathrm{NaOH}(15 \mathrm{~mL})$ and $\mathrm{Me}_{2} \mathrm{SO}_{4}(0.95 \mathrm{~mL}, 10.0 \mathrm{mmol})$ was added. The mixture was stirred for $30 \mathrm{~min}$ at room temperature followed by $2 \mathrm{~h}$ at $80^{\circ} \mathrm{C}$ while $0.7 \mathrm{M}$ $\mathrm{NaOH}$ was continuously added to keep the solution alkaline according to the procedure. The amounts of $\mathrm{Me}_{2} \mathrm{SO}_{4}$ was calculated from the total amount of free phenolic groups from the ${ }^{31} \mathrm{P}$ NMR analysis, approximately 2.5-3.0 equivalents of $\mathrm{Me}_{2} \mathrm{SO}_{4}$ per phenolic hydroxyl group was used in this work.

For the complete methylation the lignin $(2.0 \mathrm{~g})$ was dissolved in dry DMF $(30 \mathrm{~mL})$. An appropriate amount of $60 \% \mathrm{NaH}$ in mineral oil (5 equivalents with respect to the total amount of free hydroxyl groups) was measured and washed three times with hexane. The $\mathrm{NaH}$ was then stirred to a suspension with $10 \mathrm{~mL}$ dry DMF and added dropwise to the lignin solution on ice bath. The methylation agent $\mathrm{CH}_{3} \mathrm{I}$ (5 equivalents) was then added dropwise. After $16 \mathrm{~h}$ the reaction was cooled on an ice bath and the excess $\mathrm{NaH}$ was quenched by addition of $\mathrm{MeOH}$. The solution was then poured into a large volume of water and acidified to $\mathrm{pH} 2.5$ with $1 \mathrm{M} \mathrm{HCl}$. The lignin was collected by filtration and was purified twice by stirring the mixture in acidified water $(\mathrm{pH} 2.5)$ and filtering in between. After the final filtration the cake was thoroughly washed with distilled water and freeze dried prior to analysis.

\section{Conclusions}

In this study we have determined the structural characteristics and thermal properties of softwood lignins obtained from a novel PHWE process and their acetylated and methylated derivatives. It was found that the lignin from the process, which is optimized for obtaining the carbohydrate fraction from wood, clearly altered the lignin structure when compared to MWL from the same wood chips. The sulphur-free lignin shared many common traits shared among technical lignin [42] such as the reduction of the aliphatic chains and natively occurring lignin linkages. Condensed structures that had formed during the process were detected, mainly at the $\mathrm{C}_{5}-\mathrm{H}$ position of the aromatic ring. The polymeric lignin had larger amounts of carboxylic groups and free phenolic groups compared 
to MWL. The lignin from the two different softwood species showed very little differences, both structurally and in thermal properties, and can as such be used as mixtures for potential applications. The thermal properties of the softwood lignins were compared to hardwood birch lignin from the same process and the properties were similar, for both unmodified and modified lignin. It was also shown that the BLN lignin could easily be separated by solvent fractionation to prepare narrower molar mass portions with slightly different functional group compositions. The lignins had high $\mathrm{T}_{\mathrm{dst}} 95 \%$ values $\left(273-302{ }^{\circ} \mathrm{C}\right)$ and the free phenolic groups could easily be chemically modified to tailor the chemical properties, which make this lignin and its derivatives promising candidates for the use in polymer blends.

Supplementary Materials: The following are available online. Figure S1: HSQC of acetylated birch lignin, Figure S2: HSQC of acetylated pine lignin, Figure S3: HSQC of acetylated spruce lignin, Figure S4: HSQC of partially methylated birch lignin, Figure S5: HSQC of partially methylated pine lignin, Figure S6: HSQC of partially methylated spruce lignin, Figure S7: HSQC of fully methylated pine lignin, Figure S8: ${ }^{31} \mathrm{P}-\mathrm{NMR}$ of the BLN softwood lignin and MWL, Figure S9: ${ }^{31} \mathrm{P}-\mathrm{NMR}$ of the partially methylated BLN lignin, Figure S10: ${ }^{31} \mathrm{P}-\mathrm{NMR}$ of the fully methylated BLN pine lignin, Figure S11: ${ }^{31} \mathrm{P}-\mathrm{NMR}$ of the acetylated BLN lignin, Figure S12: ${ }^{31} \mathrm{P}-\mathrm{NMR}$ of the softwood lignin fractions besides the BLN lignin (MTBE insoluble), Figure S13: ${ }^{13} \mathrm{C}-\mathrm{NMR}$ of pine BLN and MWL, Figure S14: ${ }^{13} \mathrm{C}-\mathrm{NMR}$ of spruce BLN and MWL, Figure S15: ${ }^{13} \mathrm{C}-\mathrm{NMR}$ of acetylated spruce and pine BLN lignin, Figure S16: TGA of unmodified pine lignin and acetylated pine lignin.

Author Contributions: Conceptualization, L.L., A.P., S.v.S., L.V., S.W. and P.E.; methodology, L.L., A.P., S.W. and P.E.; validation, L.L.; formal analysis, L.L.; investigation, L.L., A.P. and I.S.; resources, L.L., A.P., S.v.S., L.V.; data curation, L.L.; writing—original draft preparation, L.L.; writing—review and editing, L.L., A.P., S.W. and P.E.; visualization, L.L.; supervision, S.W. and P.E.; project administration, S.W. and P.E.; funding acquisition, L.L., S.W. and P.E.

Funding: This work was funded by Suomen Luonnonvarain Tutkimussäätiö and by Fortum Säätiö project 201700061. This work is also part of the activities at the Johan Gadolin Process Chemistry Centre, a Centre of Excellence appointed by Åbo Akademi University.

Acknowledgments: Ilkka Kilpeläinen is acknowledged for supplying the MWL and Institute of Wood Technology and Renewable materials at BOKU is acknowledged for access to the TGA equipment.

Conflicts of Interest: The authors declare no conflict of interest.

\section{References}

1. Vanholme, R.; Demedts, B.; Morreel, K.; Ralph, J.; Boerjan, W. Lignin Biosynthesis and Structure. Plant Physiol. 2010, 153, 895-905. [CrossRef] [PubMed]

2. Berlin, A.; Balakshin, M. Chapter 18-Industrial Lignins: Analysis, Properties, and Applications. In Bioenergy Research: Advances and Applications; Gupta, V.K., Ed.; Elsevier: Amsterdam, The Netherlands, 2014; pp. 315-336, ISBN 978-0-444-59561-4.

3. Rinaldi, R.; Jastrzebski, R.; Clough, M.T.; Ralph, J.; Kennema, M.; Bruijnincx, P.C.A.; Weckhuysen, B.M. Paving the Way for Lignin Valorisation: Recent Advances in Bioengineering, Biorefining and Catalysis. Angew. Chem. Int. Ed. 2016, 55, 8164-8215. [CrossRef] [PubMed]

4. Cherubini, F. The biorefinery concept: Using biomass instead of oil for producing energy and chemicals. Energy. Convers. Manag. 2010, 51, 1412-1421. [CrossRef]

5. Tomani, P. The lignoboost process. Cellul. Chem. Technol. 2010, 44, 53-58.

6. $\mathrm{Pu}, \mathrm{Y}$;; Hu, F.; Huang, F.; Ragauskas, A.J. Lignin Structural Alterations in Thermochemical Pretreatments with Limited Delignification. Bioenergy Res. 2015, 8, 992-1003. [CrossRef]

7. De Menezes, F.F.; Rencoret, J.; Nakanishi, S.C.; Nascimento, V.M.; Silva, V.F.N.; Gutiérrez, A.; Del Río, J.C.; De Moraes Rocha, G.J. Alkaline Pretreatment Severity Leads to Different Lignin Applications in Sugar Cane Biorefineries. ACS Sustain. Chem. Eng. 2017, 5, 5702-5712. [CrossRef]

8. Liu, H.; Dai, Z.; Cao, Q.; Shi, X.; Wang, X.; Li, H.; Han, Y.; Li, Y.; Zhou, J. Lignin/Polyacrylonitrile Carbon Fibers: The Effect of Fractionation and Purification on Properties of Derived Carbon Fibers. ACS Sustain. Chem. Eng. 2018, 6, 8554-8562. [CrossRef] 
9. Tejado, A.; Peña, C.; Labidi, J.; Echeverria, J.M.; Mondragon, I. Physico-chemical characterization of lignins from different sources for use in phenol-formaldehyde resin synthesis. Bioresour. Technol. 2007, 98, 1655-1663. [CrossRef]

10. Kärkäs, M.D.; Matsuura, B.S.; Monos, T.M.; Magallanes, G.; Stephenson, C.R.J. Transition-metal catalyzed valorization of lignin: The key to a sustainable carbon-neutral future. Org. Biomol. Chem. 2016, 14, 1853-1914. [CrossRef]

11. Deuss, P.J.; Barta, K. From models to lignin: Transition metal catalysis for selective bond cleavage reactions. Coord. Chem. Rev. 2016, 306, 510-532. [CrossRef]

12. Sen, S.; Patil, S.; Argyropoulos, D.S. Thermal properties of lignin in copolymers, blends, and composites: A review. Green Chem. 2015, 17, 4862-4887. [CrossRef]

13. Doherty, W.O.S.; Mousavioun, P.; Fellows, C.M. Value-adding to cellulosic ethanol: Lignin polymers. Ind. Crops Prod. 2011, 33, 259-276. [CrossRef]

14. Kun, D.; Pukánszky, B. Polymer/lignin blends: Interactions, properties, applications. Eur. Polym. J. 2017, 93, 618-641. [CrossRef]

15. Upton, B.M.; Kasko, A.M. Strategies for the conversion of lignin to high-value polymeric materials: Review and perspective. Chem. Rev. 2016, 116, 2275-2306. [CrossRef] [PubMed]

16. Kim, Y.; Suhr, J.; Seo, H.; Sun, H.; Kim, S.; Park, I.; Kim, S.; Lee, Y.; Kim, K.; Nam, J. All Biomass and UV Protective Composite Composed of Compatibilized Lignin and Poly (Lactic-acid). Sci. Rep. 2017, 7, 1-11. [CrossRef]

17. Koivu, K.A.Y.; Sadeghifar, H.; Nousiainen, P.A.; Argyropoulos, D.S.; Sipilä, J. Effect of Fatty Acid Esterification on the Thermal Properties of Softwood Kraft Lignin. ACS Sustain. Chem. Eng. 2016, 4, 5238-5247. [CrossRef]

18. Dehne, L.; Vila Babarro, C.; Saake, B.; Schwarz, K.U. Influence of lignin source and esterification on properties of lignin-polyethylene blends. Ind. Crops Prod. 2016, 86, 320-328. [CrossRef]

19. Duval, A.; Lawoko, M. A review on lignin-based polymeric, micro- and nano-structured materials. React. Funct. Polym. 2014, 85, 78-96. [CrossRef]

20. Luo, S.; Cao, J.; Mcdonald, A.G. Esterification of industrial lignin and its effect on the resulting poly (3-hydroxybutyrate-co-3-hydroxyvalerate) or polypropylene blends. Ind. Crops Prod. 2017, 97, 281-291. [CrossRef]

21. Zhao, X.; Zhang, Y.; Yang, M.; Huang, Z.; Hu, H.; Huang, A.; Feng, Z. Acylation of Lignin with Different Acylating Agents by Mechanical Activation-Assisted Solid Phase Synthesis: Preparation and Properties. Polymers 2018, 10, 907. [CrossRef]

22. Gordobil, O.; Egüés, I.; Labidi, J. Modification of Eucalyptus and Spruce organosolv lignins with fatty acids to use as filler in PLA. React. Funct. Polym. 2016, 104, 45-52. [CrossRef]

23. Gordobil, O.; Egüés, I.; Llano-ponte, R.; Labidi, J. Physicochemical properties of PLA lignin blends. Polym. Degrad. Stab. 2014, 108, 330-338. [CrossRef]

24. Mu, C.; Xue, L.; Zhu, J.; Jiang, M.; Zhou, Z. Mechanical and Thermal Properties of Toughened Poly(L-lactic) Acid and Lignin Blends. BioResources 2014, 9, 5557-5566. [CrossRef]

25. Kubo, S.; Kadla, J.F. Poly (Ethylene Oxide)/Organosolv Lignin Blends: Relationship between Thermal Properties, Chemical Structure, and Blend Behavior. Macromolecules 2004, 37, 6904-6911. [CrossRef]

26. Cicala, G.; Saccullo, G.; Blanco, I.; Samal, S.; Battiato, S.; Dattilo, S.; Saake, B. Polylactide/lignin blends. J. Therm. Anal. Calorim. 2017, 130, 515-524. [CrossRef]

27. Von Schoultz, S. Method for Extracting Biomass. WO 2014/009604 A1, 16 January 2014.

28. Von Schoultz, S. Method for Extracting Lignin. WO 2015/104460 A1, 16 July 2015.

29. Lagerquist, L.; Pranovich, A.; Smeds, A.; von Schoultz, S.; Vähäsalo, L.; Rahkila, J.; Kilpeläinen, I.; Tamminen, T.; Willför, S.; Eklund, P. Structural characterization of birch lignin isolated from a pressurized hot water extraction and mild alkali pulped biorefinery process. Ind. Crops Prod. 2018, 111, 306-316. [CrossRef]

30. Cui, C.; Sadeghifar, H.; Sen, S.; Argyropoulos, D.S. Toward thermoplastic lignin polymers; Part II: Thermal \& polymer characteristics of kraft lignin \& derivatives. BioResources 2013, 8, 864-886. [CrossRef]

31. Gierer, J. Chemical Aspects of Kraft Pulping. Wood Sci. Technol. 1980, 14, 241-266. [CrossRef]

32. Lundquist, K.; Von Unge, S. Stability of arylglycerols during alkaline cooking. Holzforschung 2004, 58, 330-333. [CrossRef] 
33. Sun, S.; Yang, H.; Sun, R.; Tu, M. The strong association of condensed phenolic moieties in isolated lignins with their inhibition of enzymatic hydrolysis. Green Chem. 2016, 18, 4276-4286. [CrossRef]

34. Ralph, S.A.; Ralph, J.; Landucci, L.L. NMR Database of Lignin and Cell Wall Model Compounds. Available online: https:/ / www.glbrc.org/databases_and_software/nmrdatabase/ (accessed on 6 August 2018).

35. Domínguez-Robles, J.; Tamminen, T.; Liitiä, T.; Peresin, M.S.; Rodríguez, A.; Jääskeläinen, A.S. Aqueous acetone fractionation of kraft, organosolv and soda lignins. Int. J. Biol. Macromol. 2018, 106, 979-987. [CrossRef] [PubMed]

36. Jääskeläinen, A.S.; Liitiä, T.; Mikkelson, A.; Tamminen, T. Aqueous organic solvent fractionation as means to improve lignin homogeneity and purity. Ind. Crops Prod. 2017, 103, 51-58. [CrossRef]

37. Brebu, M.; Vasile, C. Thermal degradation of lignin-A review. Cellul. Chem. Technol. 2010, 44, 353-363.

38. Gordobil, O.; Delucis, R.; Egüés, I.; Labidi, J. Kraft lignin as filler in PLA to improve ductility and thermal properties. Ind. Crops Prod. 2015, 72, 46-53. [CrossRef]

39. Björkman, A. Studies on Finely Divided Wood. Part I. Extraction of Lignin with Neutral Solvents. Sven. Papperstidn. 1956, 59, 477-485.

40. Granata, A.; Argyropoulos, D.S. 2-Chloro-4,4,5,5-tetramethyl-1,3,2-dioxaphospholane, a Reagent for the Accurate Determination of the Uncondensed and Condensed Phenolic Moieties in Lignins. J. Agric. Food Chem. 1995, 43, 1538-1544. [CrossRef]

41. Sadeghifar, H.; Cui, C.; Argyropoulos, D.S. Toward thermoplastic lignin polymers. Part 1. Selective masking of phenolic hydroxyl groups in kraft lignins via methylation and oxypropylation chemistries. Ind. Eng. Chem. Res. 2012, 51, 16713-16720. [CrossRef]

42. Crestini, C.; Lange, H.; Sette, M.; Argyropoulos, D.S. on the Structure of Softwood Kraft Lignin. Green Chem. 2017, 19, 4104-4121. [CrossRef]

Sample Availability: Samples of the compounds are not available from the authors.

(C) 2019 by the authors. Licensee MDPI, Basel, Switzerland. This article is an open access article distributed under the terms and conditions of the Creative Commons Attribution (CC BY) license (http://creativecommons.org/licenses/by/4.0/). 